\title{
Plantas de cobertura de solo em pomar de pessegueiro (Prunus persica L. Batsch) conduzido no sistema de produção integrada
}

\author{
Cover crops manure in the peach orchard (Prunus persica L. Batsch) on integrated crop management
}

\author{
Leo Rufato ${ }^{1}$ Andrea De Rossi² ${ }^{2}$ Luciano Picolotto ${ }^{2}$ José Carlos Fachinello $^{3}$
}

\section{RESUMO}

O presente trabalho foi realizado no Pomar Didático do Centro Agropecuário da Palma do Departamento de Fitotecnia da Faculdade de Agronomia "Eliseu Maciel” da UFPEL, com o objetivo de verificar os efeitos de espécies vegetais e algumas consorciações, em cobertura de solo, sobre a cultura do pessegueiro no Sul do Brasil, em pomares conduzidos no sistema de Produção Integrada de Pêssego (PIP). Foi utilizado pomar de pessegueiro da cultivar Maciel implantado no ano de 1999, em espaçamento de 5,0 x 1,5m, com dois sistemas de condução, Líder Central (LC) e Ypsilon (Y). Os tratamentos constaram de cinco espécies de plantas para cobertura vegetal de inverno, quatro consorciações entre estas espécies, mais a testemunha (vegetação espontânea). Foram analisadas as variáveis incremento no diâmetro do tronco das plantas, incremento no volume de copa, índice de fertilidade, produção por planta, matéria fresca e matéria seca das coberturas vegetais. Os maiores benefícios em termos de produtividade foram obtidos pela associação das coberturas vegetais, com a maior média alcançada com a associação de aveia preta + ervilha forrageira. As coberturas vegetais não tiveram efeito sobre o diâmetro do tronco das plantas de pessegueiro, porém interferiram principalmente no volume da copa, na produtividade e no índice de fertilidade.

Palavras-chave: produção integrada de frutas, crescimento vegetativo, produtividade, manejo do solo.

\section{ABSTRACT}

This research was carried out in the South of Brazil with the objective to examine the effects of five cover crops and their combinations on peach orchard leaded in Integrated Crop Management. The experimental orchard was installed in 1999 at $1.5 \times 5.0 m$ planting density, with two training systems: Central Leader (CL) and Ypsilon Shape (Y). The increment on trunk diameter, the increment on foliage size, the frequency productive buds, fruit yield, fresh and dry matter were evaluated.
The combination of different cover crops was beneficial considering the productivity with distinction to the Avena strigosa+Pisum sativum combination. The trunk diameter of peach tree was not influenced by cover crops. Nevertheless, the foliage size, frequency productive of buds, and productivity were significantly affected by the cover crops.

Key words: integrate crop management, vegetative development, productivity, soil management.

\section{INTRODUÇÃO}

No Sul e no Sudeste do Brasil, nas décadas de 40 e 50, a adubação verde e a rotação de culturas foram práticas agrícolas recomendadas pelos órgãos oficiais, que faziam orientação e assistência técnica. Entretanto, a facilidade de uso e os altos níveis de resposta da adubação mineral contribuíram para diminuir o interesse pela adubação verde.

Recentemente, o crescente aumento de preço dos insumos e o declínio da produtividade, decorrente do mau uso dos solos, fizeram com que os agricultores voltassem sua atenção para a prática da adubação verde. A adubação verde, embora não substitua, pode complementar a mineral, diminuindo as despesas do produtor (SCHREINER, 1988). Ela atua na manutenção ou na restauração da estrutura dos solos, podendo também enriquecê-lo com nitrogênio, devido à fixação biológica (PHILIPOVSKY et al., 2000).

Para as condições específicas de fruteiras de caroço, no sul do Brasil, não se dispõe de resultados sobre as espécies e os procedimentos mais adequados

\footnotetext{
${ }^{1}$ Faculdade de Agronomia Eliseu Maciel (FAEM), Universidade Federal de Pelotas (UFPel), Pelotas, RS, Brasil. E-mail: leoruffato@yahoo.com.br.

${ }^{2}$ Mestrando do Curso de Pós-graduação em Agronomia da UFPel, Pelotas, RS, Brasil.

${ }^{3}$ Departamento de Fitotecnia, FAEM/UFPel, Pelotas, RS. Brasil.
} 
da cobertura do solo. A técnica de gestão dos pomares de pêssego tem sofrido uma notável transformação na última década. No passado, as intervenções culturais eram direcionadas à maximização da produção, atualmente os objetivos também são a melhoria da qualidade do produto e a maior integração entre a fruticultura e o ambiente (MARANGONI et al., 1995).

Segundo as recomendações para a Produção Integrada de Pêssego - PIP(FACHINELLO et al., 2003), as intervenções culturais destinadas ao solo devem maximizar a sua potencialidade natural e reduzir ao mínimo os aportes externos e o uso de produtos de síntese (fertilizantes, dessecante, etc.).

A cobertura do solo é uma alternativa ecológica e econômica de conduzir o solo, possibilitando equilíbrio das propriedades físicas, químicas e biológicas que giram em torno do sistema solo-planta.

Não é aconselhável introduzir a cobertura, mesmo parcial, no primeiro ano de plantio, pelo risco de debilitar excessivamente as plantas em fase de formação, cujo sistema radicular está pouco desenvolvido e é mais sensível à competição da cobertura vegetal (MARANGONI et al., 2002).

Embora a maneira mais simples para constituir uma cobertura vegetal seja deixar desenvolverem-se as espécies espontâneas da região (cobertura espontânea), o plantio de espécies oportunamente selecionadas permite a obtenção de importantes resultados como o rápido estabelecimento e a cobertura do solo.

A composição inicial da cobertura sofre, com o decorrer do tempo, uma inevitável dinâmica evolutiva. Não se consegue mais, de fato, substituir totalmente e de maneira definitiva a flora autógama. Como resultado, ao passar dos anos, a cobertura vegetal possui maior variedade florística. Porém, segundo o mesmo autor, tanto a cobertura vegetal temporária como a permanente foram capazes de fornecer elevadas quantidades de biomassa (RANDI, 1999).

O objetivo deste trabalho foi verificar os efeitos de espécies vegetais e algumas consorciações, em cobertura de solo, sobre pomar de pessegueiro no Sul do Brasil, conduzido no sistema de Produção Integrada de Pêssego (PIP).

\section{MATERIAL E MÉTODOS}

O presente trabalho foi realizado no Pomar Didático do Centro Agropecuário da Palma do Departamento de Fitotecnia da Faculdade de Agronomia “Eliseu Maciel” da UFPEL. Para execução do experimento, foi utilizado pomar de pessegueiro da cultivar Maciel implantado no ano de 1999, em espaçamento de 5,0 x 1,5m, com dois sistemas de condução, Líder Central (LC) e Ypsilon (Y).

O experimento foi conduzido por três anos consecutivos (2000, 2001 e 2002), com o cultivo de plantas de cobertura vegetal de inverno. As coberturas vegetais de solo foram implantadas em parcelas de dimensões de 4 X 5 metros, com bordadura de 1 metro, mantida com aveia preta. As parcelas foram implantadas no pomar, de modo a conterem três plantas de pessegueiro em cada unidade experimental e uma planta de pessegueiro entre as parcelas como bordadura. Os tratamentos constaram das seguintes espécies de plantas para cobertura vegetal de inverno: aveia preta (Avena strigosa Schreb), chícharo (Lathyrus sativus L.), ervilha forrageira (Pisum sativum subesp. arvense), nabo forrageiro (Raphanus sativus L. var. oleiferus Metzg), tremoço azul (Lupinus angustifolius L.), e quatro consorciações entre as espécies (aveia preta/ ervilha forrageira; aveia preta/nabo forrageiro, aveia preta/chícharo, nabo forrageiro/ervilha forrageira) e a testemunha (com vegetação espontânea).

O preparo inicial do solo foi realizado com uma gradagem leve e posterior semeadura das coberturas vegetais. No ano subseqüente, realizou-se a semeadura das coberturas sobre a palha acamada das próprias coberturas vegetais. Para cobrir as sementes, utilizou-se uma grade de disco leve, evitando o revolvimento do solo. O plantio das coberturas vegetais foi realizado em 03/06/2000 e em 20/06/2001 e seu manejo deu-se com acamamento com grade de disco "não-travada" no mês de novembro dos respectivos anos. No verão, a vegetação espontânea foi mantida roçada a $5 \mathrm{~cm}$ do solo. Durante a condução do experimento, foram seguidas as recomendações da Produção Integrada do Pêssego - PIP (FACHINELLO et al., 2003). avaliados:

A seguir são descritos os parâmetros

1) incremento no diâmetro do tronco dos pessegueiros: medida realizada nos dois anos consecutivos de condução do experimento (2000/2001), com o qual se obteve a diferença entre a medida inicial e a final, durante o período de repouso vegetativo das plantas. Foram medidos os diâmetros longitudinal e transversal à linha de plantio do tronco a $20 \mathrm{~cm}$ do nível do solo, com paquímetro digital, obtendo-se a média entre as duas medidas;

2) incremento no volume de copa: medida realizada nos dois anos consecutivos de condução do experimento (2000/2001), com o qual se obteve a diferença entre a medida inicial e a final através dos comprimentos longitudinal (L), transversal (T) e altura 
(H) da copa dos pessegueiros, medidos durante o período de repouso vegetativo das plantas, antes da intervenção de poda. O cálculo do volume de copa foi obtido através da fórmula $V=\left(\pi r^{2} h\right.$ / 3; onde $V=$ volume; $\mathrm{r}=$ raio $(\mathrm{L} / 2 . \mathrm{T} / 2)$ e $\mathrm{h}=$ altura;

3) índice de fertilidade das gemas: foi avaliado somente no inverno de 2001, com amostragem de cinco ramos de cada planta de pessegueiro. Realizouse a contagem do número de pares de gemas floríferas no ramo e de seu respectivo comprimento, determinando o índice de fertilidade através da relação direta entre o número de pares de gemas floríferas e o comprimento do ramo;

4) produção por planta: nos anos de 2000, 2001 e 2002, foram colhidas e pesadas todas as frutas das parcelas, em três a quatro repasses por colheita, sendo os dados expressos em quilograma de fruta por planta. A realização de mais uma colheita em 2002 foi para verificar o possível efeito residual das coberturas sobre as plantas;

5) matéria fresca e matéria seca da parte aérea das coberturas vegetais: anteriormente à instalação dos tratamentos, realizou-se a coleta de um metro quadrado da parte aérea das plantas utilizadas em cobertura vegetal do solo de cada tratamento, mais a testemunha, realizando-se a pesagem da matéria fresca e, posteriormente, a secagem em estufa a $60^{\circ} \mathrm{C}$ por 36 horas e a pesagem da matéria seca.

O delineamento experimental utilizado foi o de blocos completamente casualizados com três repetições e três plantas por parcela, com os tratamentos arranjados em parcelas subdivididas, considerando como parcela principal as coberturas vegetais e como subparcelas os sistemas de condução, em um total de 20 tratamentos. Os dados foram submetidos à análise da variância pelo teste $\mathrm{F}$ e à análise de comparação de médias através do teste de Duncan a $\mathrm{P} \geq 5 \%$ de probabilidade. Os dados da variável volume de copa foram submetidos à transformação de raiz quadrada de X+0,5 e, para a variável diâmetro do tronco os dados foram submetidos à transformação de raiz quadrada de $\mathrm{X}+1$, analisados através do programa SANEST (ZONTA \& MACHADO, 1995).

\section{RESULTADOS E DISCUSSÃO}

O sistema de condução em líder central (LC) apresentou maior incremento no volume de copa, porém com a copa mais compactada em relação ao sistema em ypsilon (Y) (Tabela 1). Por ser uma forma de condução mais livre, onde não foram realizadas intervenções de poda expressivas, a planta pôde manifestar o desenvolvimento vegetativo quase na sua totalidade, ao contrário do sistema Y, que teve comportamento mais direcionado com poda para facilitar a abertura dos ramos. O peso seco total da copa das plantas conduzidas em LC é normalmente o dobro das plantas conduzidas em Y. Para os demais parâmetros, não foram observadas diferenças significativas entre os sistemas de condução (GIOVANINI \& MONASTRA, 1998).

Analisando-se o efeito individual das coberturas vegetais no incremento no volume de copa para os dois sistemas de condução (Tabela 1), verificase maior incremento nesta variável com cobertura vegetal de tremoço azul e menor incremento com a cobertura de nabo forrageiro. Os demais tratamentos foram estatisticamente semelhantes tanto ao nabo forrageiro quanto ao tremoço azul. Resultados semelhantes foram encontrados por RUFATO (2004), que constatou efeito positivo do tremoço azul no diâmetro do tronco, no comprimento de ramos e no volume de copa para plantas de pessegueiro cultivar Maciel e menores índices, nas mesmas variáveis, para o nabo forrageiro. Em condições de bioteste, houve um efeito alelopático do nabo forrageiro sobre o desenvolvimento de plantas de feijão, milho e soja (ALMEIDA \& RODRIGUES, 1985). As substâncias ativas no processo de alelopatia das crucíferas são os glucosinatos (glucosídeos que contêm enxofre) (ALPI et al., 2001).

Não foi observado efeito significativo das coberturas vegetais sobre o incremento do diâmetro do tronco (Tabela 1).

$\mathrm{Na}$ avaliação do índice de fertilidade dos ramos de pessegueiro, observou-se, no sistema Y, que somente o tratamento com ervilha forrageira diferiu estatisticamente da testemunha e do chícharo. Para o sistema LC, a consorciação de aveia preta + nabo forrageiro teve os maiores índices $(0,51)$, porém diferido estatisticamente somente da combinação de nabo forrageiro + ervilha forrageira. Os dados de índice de fertilidade são, usualmente, utilizados para avaliar as características de cultivares em diferentes locais de produção. O índice de fertilidade médio para cultivares de pêssego está em torno de 0,30. O mesmo autor não observou diferenças em pessegueiro da cultivar Roza entre solo coberto com gramíneas e solo gradeado (RANDI, 1999).

Com relação à produção por planta, a análise dos dados mostrou ocorrer interação significativa entre os tratamentos, porém destaca-se, na figura 1, que, entre os dois sistemas de condução, durante os 3 anos, o LC foi significativamente superior ao Y.

Analisando separadamente os sistemas de condução dentro das coberturas vegetais, verifica-se que, para o sistema Y (Figura 2), não houve diferença 
Tabela 1 - Parâmetros vegetativos de plantas de pessegueiro conduzidas em ypsilon (Y) e líder central (LC), em função de diferentes coberturas vegetais, sob o sistema de produção integrada de pessegueiro - PIP. FAEM/UFPel, Pelotas, 2004.

\begin{tabular}{|c|c|c|c|c|c|c|c|c|c|c|c|c|}
\hline \multirow{4}{*}{$\begin{array}{l}\text { Coberturas/ Sistemas } \\
\text { Aveia preta }\end{array}$} & \multicolumn{4}{|c|}{$\begin{array}{l}\text { Incremento no diâmetro do } \\
\text { tronco }(\mathrm{mm})\end{array}$} & \multicolumn{4}{|c|}{$\begin{array}{l}\text { Incremento no volume } \\
\text { de copa }\left(\mathrm{m}^{3}\right)\end{array}$} & \multicolumn{4}{|c|}{$\begin{array}{l}\text { Índice de Fertilidade } \\
\quad\left(\text { gemas } \mathrm{cm}^{-1}\right)\end{array}$} \\
\hline & \multicolumn{4}{|c|}{$2000 / 2001$} & \multicolumn{4}{|c|}{$2000 / 2001$} & \multicolumn{4}{|c|}{2001} \\
\hline & \multicolumn{2}{|c|}{$\mathrm{Y}$} & \multicolumn{2}{|c|}{ LC } & \multicolumn{2}{|c|}{$\mathrm{Y}$} & \multicolumn{2}{|c|}{ LC } & \multicolumn{2}{|c|}{$\mathrm{Y}$} & \multicolumn{2}{|c|}{$\mathrm{LC}$} \\
\hline & 16,06 & $\mathrm{a}$ & 22,22 & a & 0,39 & $\mathrm{ab}$ & 0,49 & $a b$ & 0,44 & $\mathrm{ab}$ & 0,48 & $a b$ \\
\hline Nabo forrageiro & 17,81 & a & 15,79 & a & 0,31 & $\mathrm{~b}$ & 0,44 & b & 0,44 & $\mathrm{ab}$ & 0,49 & $\mathrm{ab}$ \\
\hline Chícharo & 20,83 & a & 16,79 & a & 0,56 & $\mathrm{ab}$ & 0,64 & $\mathrm{ab}$ & 0,43 & $\mathrm{~b}$ & 0,47 & $\mathrm{ab}$ \\
\hline Ervilha forrageira & 22,62 & $\mathrm{a}$ & 17,37 & a & 0,47 & $\mathrm{ab}$ & 0,62 & $\mathrm{ab}$ & 0,50 & $\mathrm{a}$ & 0,47 & $\mathrm{ab}$ \\
\hline Aveia preta+ervilha forrageira & 20,08 & a & 18,85 & a & 0,42 & $a b$ & 0,51 & $\mathrm{ab}$ & 0,46 & $\mathrm{ab}$ & 0,48 & $\mathrm{ab}$ \\
\hline Aveia preta+nabo forrageiro & 19,18 & $\mathrm{a}$ & 16,96 & a & 0,58 & $\mathrm{ab}$ & 0,73 & $\mathrm{ab}$ & 0,48 & $\mathrm{ab}$ & 0,51 & a \\
\hline Nabo forrageiro+ervilha forrageira & 17,54 & a & 19,99 & a & 0,54 & $\mathrm{ab}$ & 0,69 & $\mathrm{ab}$ & 0,48 & $a b$ & 0,43 & $\mathrm{~b}$ \\
\hline Aveia preta+chícharo & 19,02 & a & 18,25 & a & 0,60 & $\mathrm{ab}$ & 0,58 & $\mathrm{ab}$ & 0,45 & $a b$ & 0,47 & $\mathrm{ab}$ \\
\hline Testemunha & 19,74 & $\mathrm{a}$ & 21,10 & a & 0,39 & $a b$ & 0,56 & $\mathrm{ab}$ & 0,42 & $\mathrm{~b}$ & 0,48 & $a b$ \\
\hline Tremoço azul & 20,20 & a & 18,69 & a & 0,65 & $\mathrm{a}$ & 0,76 & $\mathrm{a}$ & 0,46 & $a b$ & 0,45 & $a b$ \\
\hline \multicolumn{13}{|l|}{ Média condução } \\
\hline Ypsilon & & 19,31 & a & & & 0,49 & $\mathrm{~b}$ & & & 0,46 & a & \\
\hline Líder central & & 18,60 & $\mathrm{a}$ & & & 0,60 & $\mathrm{a}$ & & & 0,47 & $\mathrm{a}$ & \\
\hline
\end{tabular}

Médias seguidas por letras distintas na mesma coluna diferem entre si pelo teste de Duncan a 5\% de probabilidade de erro.

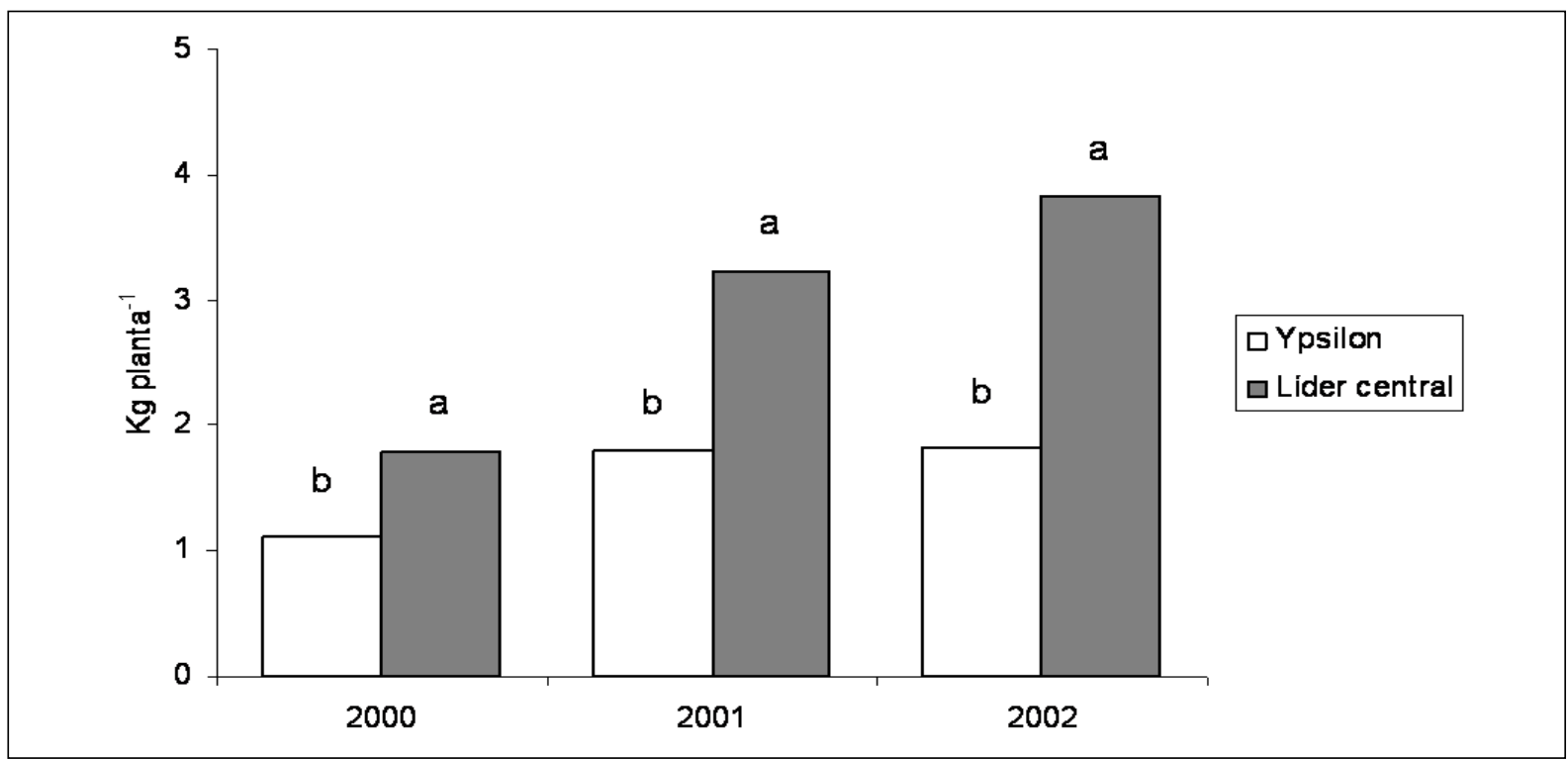

Figura 1 - Produção por planta em pomar de pessegueiro da cultivar Maciel conduzido em Ypsilon e Líder Central sob o sistema de produção integrada de pêssego-PIP, em três agrícolas. FAEM/UFPEL, Pelotas, 2004. Letras distintas diferem entre si pelo teste de Duncam 5\% de probabilidade de erro. 


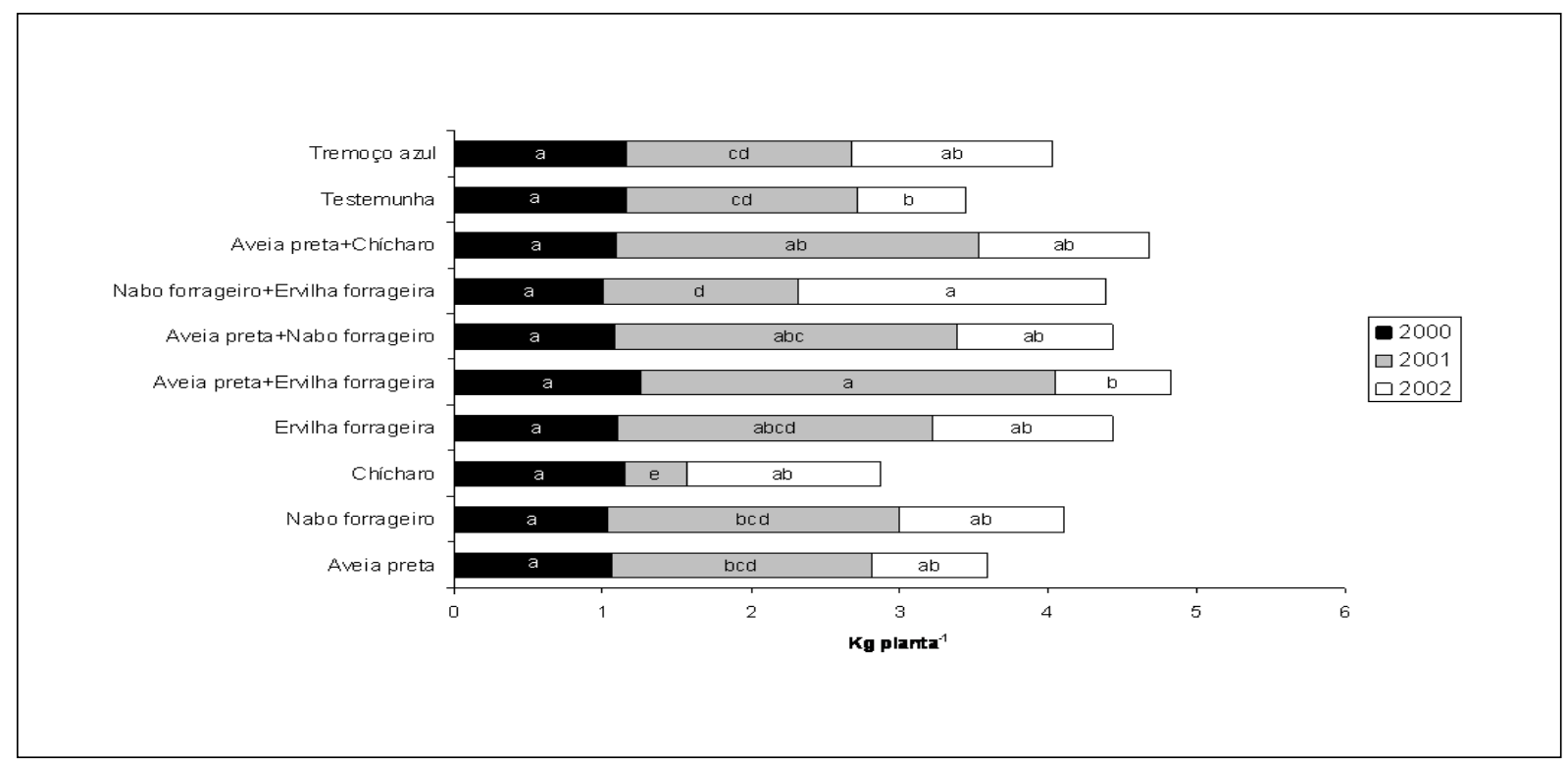

Figura 2 - Produção por planta em pomar de pessegueiro da cultivar Maciel conduzido em Ypsilon, sob o sistema de produção interada de pêssedo-PIP, em função de espécies utilizadas em cobertura vegetal, em três anos agrícolas. FAEM/UFPel, Pelotas, 2004. Letras distintas dentro dos anos avaliados diferem entre si pelo teste de Duncan em nível de 5\% de probabilidade de erro.

significativa no primeiro ano (2000). No ano subseqüente, o tratamento de aveia preta + ervilha forrageira apresentou o melhor resultado em termos de produção por planta, juntamente com aveia preta + nabo forrageiro e aveia preta + chícharo, porém, no terceiro ano, somente foi observada diferença estatística entre a cobertura de nabo forrageiro + ervilha forrageira e com as coberturas de aveia preta + ervilha forrageira e testemunha.

Na média dos três anos, todas as coberturas foram superiores ao chícharo isoladamente e, de modo geral, as consorciações proporcionaram maior quantidade produzida que as coberturas plantadas individualmente, o que demonstra o efeito benéfico do sinergismo entre as espécies de cobertura vegetal em relação à produção do pessegueiro. Os efeitos da cobertura vegetal de chícharo, na produção por planta, foram inferiores até mesmo à testemunha (Figura 2).

Para o sistema LC (Figura 3), observou-se que, no primeiro ano, a testemunha apresentou a melhor produção por planta, juntamente com aveia preta e tremoço azul. No segundo ano, o tratamento aveia preta

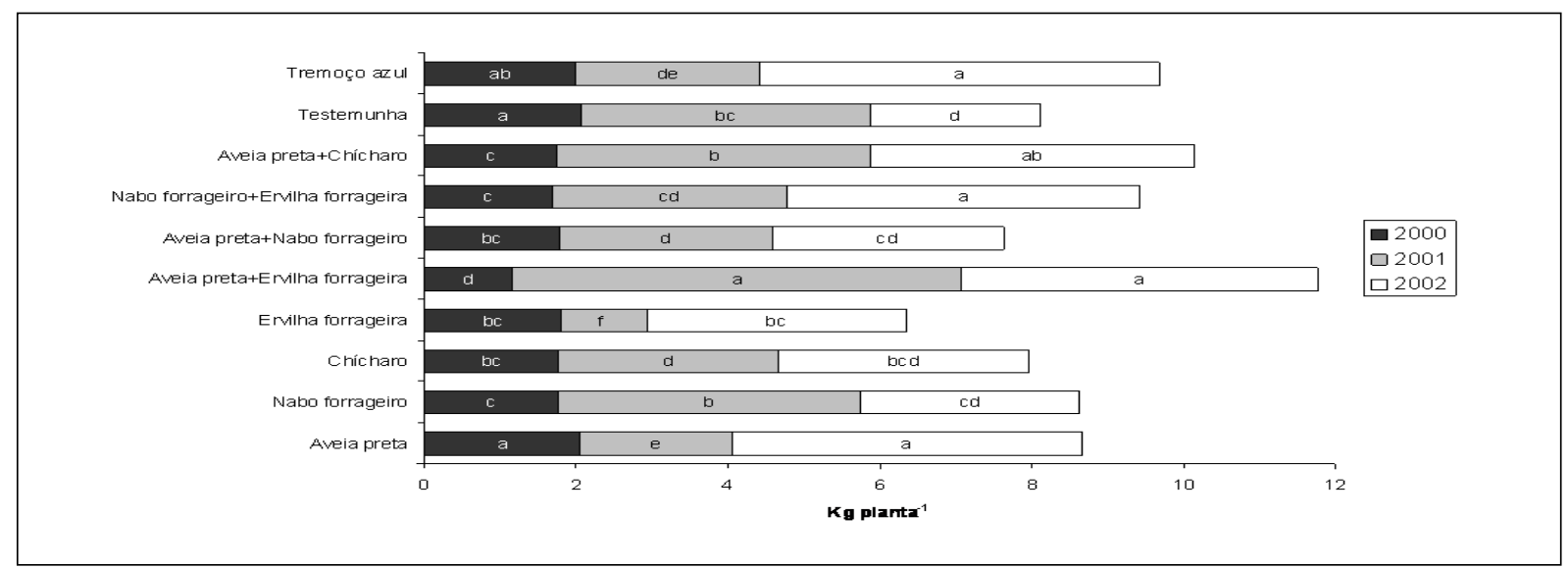

Figura 3 - Produção por planta em pomar de pessegueiro da cultivar Maciel conduzido em Líder Central, sob o sistema de produção integrada de pêssego-PIP, em função de espécies utilizadas em cobertura vegetal, em três anos agrícolas. FAEM/UFPel, Pelotas, 2004.

Letras distintas dentro de cada ano avaliado diferem entre si pelo teste de Duncan em nível de $5 \%$ de probabilidade de erro.

Ciência Rural, v.36, n.3, mai-jun, 2006. 
+ ervilha forrageira, do mesmo modo ao que foi observado no sistema $\mathrm{Y}$, foi o que propiciou maior produção por planta. No terceiro ano, observou-se maior uniformidade de produção entre as coberturas vegetais, onde os melhores resultados foram alcançados com os tratamentos que, de um modo geral, possuíam uma leguminosa isolada ou em consorciação e, igualmente ao sistema $\mathrm{Y}$, a testemunha foi significativamente menos produtiva que os demais tratamentos, não diferindo, porém, dos tratamentos aveia preta + nabo forrageiro, chícharo e nabo forrageiro isolado.

O efeito positivo da consorciação de aveia preta + ervilha forrageira, na produção por planta, pode estar relacionado à rápida disponibilização de nutrientes. Como a aveia possui alta relação $\mathrm{C} / \mathrm{N}$, necessita de $\mathrm{N}$ externo para sua completa decomposição (FERREIRA et al, 2000) e a ervilha forrageira, por sua vez, é capaz de fixar simbioticamente até $140 \mathrm{~kg} \mathrm{ha}^{-1}$ de $\mathrm{N}$. Neste estudo, o $\mathrm{N}$ fixado simbioticamente pela ervilha pode ter colaborado para acelerar a decomposição da aveia e, conseqüentemente, a disponibilização de nutrientes para as plantas de pessegueiro (TISDALE et al., 1985).

Observou-se que as coberturas de solo com crucíferas e leguminosas, com exceção do tremoço azul, mantiveram o solo coberto por um menor período, diferentemente da aveia, que manteve sua cobertura por um período mais prolongado (dados não apresentados). A maior permanência dos restos culturais da aveia é justificada pela elevada relação C/ N que, segundo FIORIN (1999), é em torno de 34.
A quantidade de matéria seca em cobertura necessária para evitar problemas de erosão é em torno de $1 \mathrm{t} \mathrm{ha}^{-1}$. Como se observa nas figuras 4 e 5 , em todos os tratamentos obtiveram-se quantidades superiores a 3t ha-1 ${ }^{-1}$ FERREIRA \& SCHWARZ, 2000). De acordo com RAMOS (1976), quantidades de 4,4t ha-1 foram suficientes para propiciar a infiltração de $100 \%$ da água de uma chuva de $40 \mathrm{~mm}$. O fato de as coberturas alcançarem tais quantidades de matéria seca em cobertura resultou em benefício imediato na proteção do solo contra o escorrimento superficial.

No sistema LC para matéria seca e matéria fresca (Figura 4) produzidas pelas espécies de cobertura vegetal e suas combinações, verifica-se que o tratamento de aveia preta+nabo forrageiro teve a maior quantidade produzida de MS. Para MF, as coberturas de aveia preta+nabo forrageiro e de nabo forrageiro isoladamente tiveram as maiores quantidades produzidas. Mesmo em condições de sombreamento proporcionado pelo sistema LC, o nabo se desenvolve bem. A consorciação com aveia preta trouxe o benefício de estender o período de cobertura do solo devido à alta relação $\mathrm{C} / \mathrm{N}$ da aveia, conforme discutido anteriormente. As demais coberturas e consorciações tiveram um comportamento similar, não sendo inferior a $6 \mathrm{t} \mathrm{ha}^{-1}$.

Observa-se, na figura 5, que, no sistema de condução Y, as consorciações de aveia preta + nabo forrageiro, aveia preta + ervilha forrageira e o nabo forrageiro isoladamente obtiveram as maiores quantidades de MF. Porém, as diferenças de MS

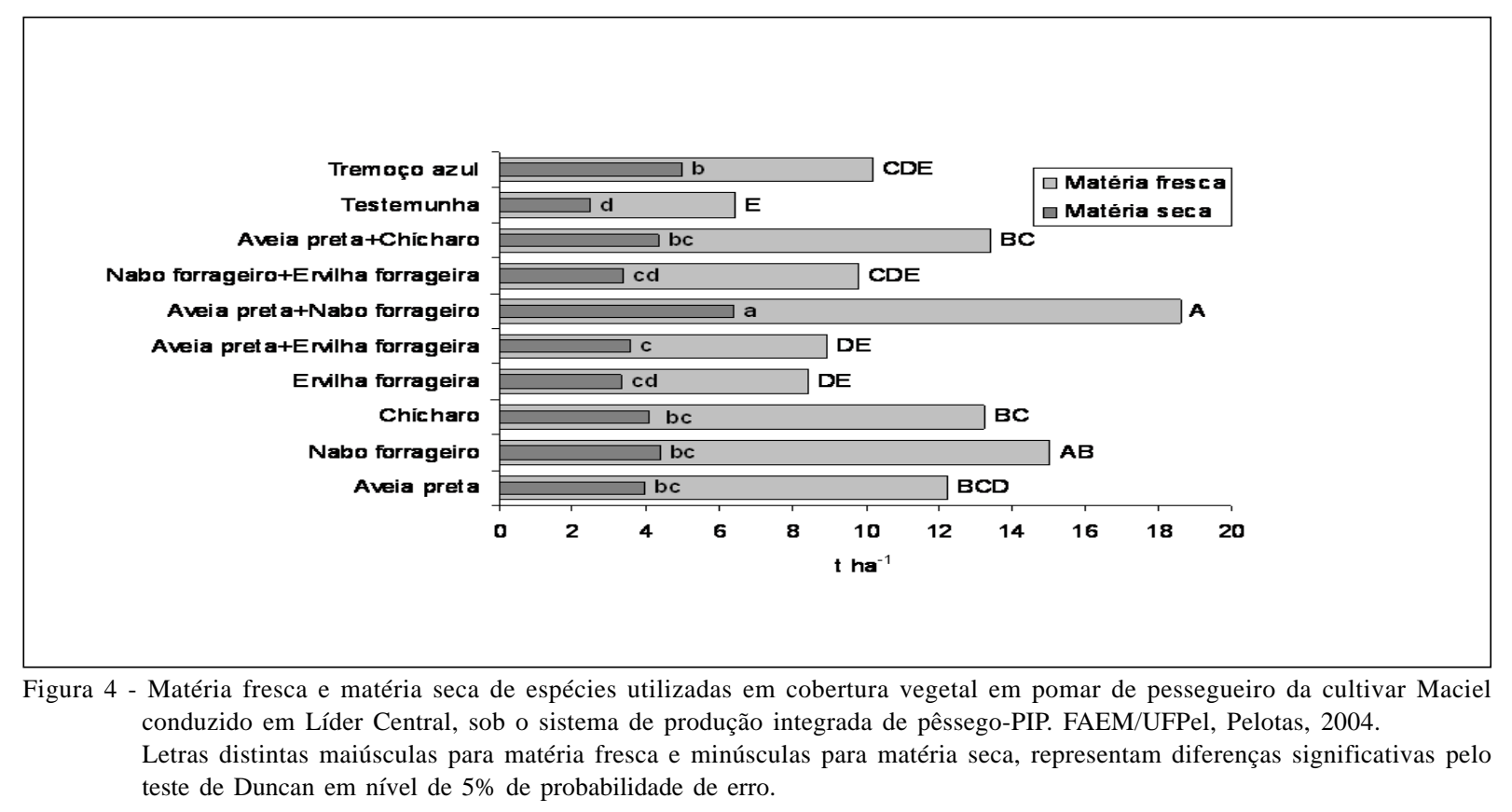

Ciência Rural, v.36, n3, mai-jun, 2006. 


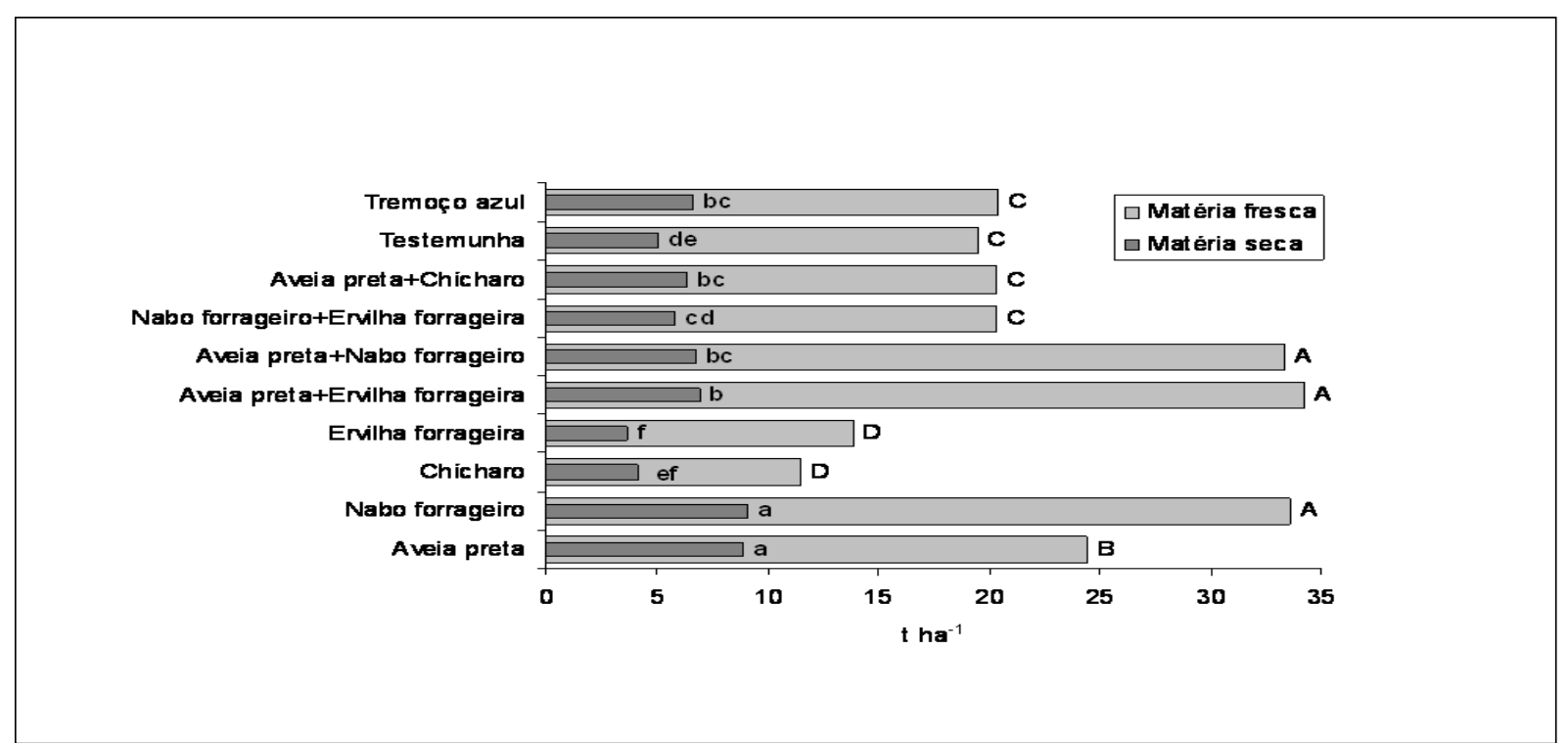

Figura 5 - Matéria fresca e matéria seca de espécies utilizadas em cobertura vegetal em pomar de pessegueiro da cultivar Maciel conduzido em "Ypsilon", sob o sistema de produção integrada de pêssego-PIP, em três anos agrícolas. FAEM/UFPel, Pelotas, 2004.

Letras distintas maiúsculas para matéria fresca e minúsculas para matéria seca representam diferenças significativas pelo teste de Duncan em nível de 5\% de probabilidade de erro.

somente foram mantidas para as espécies isoladas nabo forrageiro $\left(9,06 \mathrm{tha}^{-1}\right)$ e aveia preta $\left(8,92 \mathrm{tha}^{-1}\right)$.

\section{CONCLUSÕES}

As coberturas vegetais não têm efeito sobre o diâmetro do tronco das plantas de pessegueiro, porém interferem no volume de copa, na produção e no índice de fertilidade das plantas de pessegueiro. O emprego do nabo forrageiro em pomares deve ser mais bem estudado, devido ao seu possível efeito alelopático em plantas de pessegueiro. A aveia preta, com todas consorciações estudadas, demonstra boa aplicabilidade dentro do sistema de produção, tanto para condução em YeLC.

\section{AGRADECIMENTOS E APRESENTAÇÃO}

Agradecemos ao Dr. Luis Marcolina, da Estação Experimental do Instituto Agronômico do Paraná (IAPAR Pato Branco), pela disponibilização das sementes das coberturas vegetais utilizadas neste estudo, ao Conselho Nacional de Desenvolvimento Científico e Tecnológico (CNPq) e à Coordenação de Aperfeiçoamento de Pessoal de Nível Superior (CAPES), pelo apoio financeiro.

Parte da tese de doutorado do primeiro autor.

\section{REFERÊNCIAS}

ALMEIDA, F.S.; RODRIGUES, B.N. Plantio direto. In: Guia de herbicidas; contribuição para o uso adequado em plantio direto e convencional. Londrina: IAPAR, 1985. p.341-399.
ALPI, A. et al. Fisiologia delle piante. Napoli: EdiSES S.r.l., 2001. 560p.

FACHINELLO, J.C. et al. Normas técnicas e documentos de acompanhamento da produção integrada de pêssego. Pelotas: UFPel/FAEM, 2003. 92p.

FERREIRA, T.N.; SCHWARZ, R.A. Solos: manejo integrado e ecológico - elementos básicos. Porto Alegre: EMATER/ RS, 2000. 95p.

FIORIN, J.E. Plantas recuperadoras da fertilidade do solo. In: CURSO SOBRE ASPECTOS BÁSICOS DE FERTILIDADE E MICROBIOLOGIA DO SOLO EM PLANTIO DIRETO FERTILIDADE DO SOLO EM PLANTIO DIRETO, 1999, Cruz Alta. Resumos... Passo Fundo: Aldeia Norte, 1999. p.39-55.

GIOVANNINI, D.; MONASTRA, F. Tipologie d'impianto e forme di allevamento per la peschicoltura meridionale. In: SANSAVINI, S.; ERRANI, A. Frutticoltura ad alta densità - Impianti, forme de allevamento e tecniche di potatura. Bologna: Edagricole, 1998. p.217-235.

MARANGONI, B. et al. Relazione tra nutrizione azotata e metabolismo delle piante. Rivista di Frutticoltura e di Ortofloricoltura, Bologna, v.LVII, p.7-8, 1995.

MARANGONI, B. et al. Agronomia sostenible de los cultivos leñosos. In: JORNADAS DE AIDA: PRODUCCIÒN SOSTENIBLE EN EL MEDIO AGRARIO, 34., 2002, Zaragoza. Atti... Zaragoza: ITEA, 2002. p.32-51.

PHILIPOVSKY, J.F. et al. Avaliação de diferentes coberturas do solo no inverno para associação com a cultura da erva mate, no município de Ponta Grossa Paraná. Pesquisa em Andamento, Brasília, n.93, p.1-5, 2000. 
RANDI, M. Influenza della gestione del terreno sul comportamento vegeto-produttivo di un pescheto biologico. 1999. 123f. Monografia (Graduação em Agronomia) - Facoltà di Agrária, Università Degli Studi di Bologna.

RUFATO, L. Influência da cobertura vegetal no desenvolvimento vegetativo de plantas de pessegueiro e na evolução da população de fitonematóides de solo. 2004 101f. Tese (Doutorado em Agronomia) - Programa de Pósgraduação em Agronomia, Universidade Federal de Pelotas.
SCHREINER, H.G. Associação de leguminosas com plantios florestais para cobertura e melhoramento do solo. Boletim de Pesquisa Florestal, Colombo, n.17, p.1-12, 1988.

TISDALE, S.L. et al. Soil fertility and fertilizers. 4.ed. New York: Macmillan, 1985. 754p.

ZONTA, E.P.; MACHADO, A.A. Sanest - Sistema de análise estatística para microcomputadores. Pelotas, UFPel, 1995. 48p. (SEI n.066060, Categoria A). 